\title{
FÜTÜRİZM'İN MÜZİĞE ETKİLERİ VE YENI ÇALGILAR
}

\author{
FUTURIST INFLUENCES IN MUSIC AND NEW INSTRUMENTS
}

Rohat CEBE $^{1}$

\section{Öz}

Orta Çağ’dan başlayarak 19.yüzyılın sonuna kadar, sıra dışı ses efektlerinin ilginç örneklerine rastlasak da sadece uyumsuzluğun değil aynı zamanda gürültünün de ortaya atılma fikri özellikle 20.yüzyıla ait bir olgudur. $\mathrm{Bu}$ yüzyılın ilk çeyreğinde filizlenmeye başlayan, öncelikle görsel sanatlar ve edebiyatta önemli bir yere sahip olan Fütürizm akımının etkisiyle, müzikte yeni ve farklı sesler yaratma arzusu doruk noktasına ulaşmış, klasik çalgılardan bağımsız olarak yeni çalgılar icat edilmiş ve doğal müzik tınısı bir anlamda mekanik seslerle bütünleştirilmeye çalışılmıştır. İşte bu noktada Fütürizm'in müziğe etkileri ve yeni çalgılar isimli makale, bu yeni ve farklı sesler yaratma arzusunun 20.yüzyılın başlarından günümüze kadar olan süreç içerisindeki gelişimini özetlemeye çalışmıștır. 1900'lu yılların başlarında zirvede olan Fütürist akımın müziğe etkileri, bu etkiler paralelinde ortaya çıkan yeni fikirler ve bu yeni fikirlerin uzantısı olarak icat edilen yeni çalgılar görsel materyal de kullanılarak anlatılmaya çalışılmıştır.

Anahtar Kelimeler: Fütürizm, Yeni Çalgılar, 20. Yüzyıl Müziği.

\begin{abstract}
Although we encounter noteworthy examples of unusual sound effects starting with the Middle Ages until the end of the 20th Century, the idea of opening not only dissonance but also noise to discussion is especially a 20th Century phenomenon. New instruments, independent of conventional instruments, were invented, and natural music timbre, in a sense, was attempted to be combined with mechanical sounds with the influence of the Futurist movement, which started to emerge in the first quarter of the 20th century, that had an important role in the visual arts and literature. The article "Futurist Influences in Music and New Instruments", at this point, describes the development of the desire to create new and different sounds starting from the early 20th Century up to the present. Reaching its peak in the early $20^{\text {th }}$ century, Futurist movement has had profound effects on music; new ideas that appeared in parallel with these effects, and new instruments invented as a result of these ideas have been explained using visual material.
\end{abstract}

Key Words: Futurism, New Instruments, 20th Century Music.

\footnotetext{
${ }^{1}$ Yrd.Doç.Dr., Batman Üniversitesi, Güzel Sanatlar Fakültesi, rohatcebe@ hotmail.com
} 


\section{FÜTÜRIZZM VE ETKİLERİ}

1909 ve 1919 yılları arasında zirvede olan Fütürist akım, görsel sanatlar ve edebiyatta önemli bir role sahipti. Fütürizm hareketinin kurucusu 1876 ile 1944 yılları arasında yaşamış İtalyan şair ve yazar Filippo Tommaso Marinetti'dir. 'Özgürlükteki kelimeler' olarak çevrilebilecek, parole in liberta konseptini icat eden Marinetti'nin şiirlerindeki alan, sayfa ile birlikte sesi de içerir. Şiirleri; paragraf, dörtlük ve satırın zulmünden kurtarılmış, sayfa etrafinda uçuşan kelimelerden oluşur. En ünlü şiiri olan 1926 tarihli 'Bombardamento di Adrianapoli”nin kaydında, aslında Marinetti'yi ağzıyla savaş seslerini çıkarırken duyabiliriz. Makineli tüfekler takırdar ve kanonlar büyük bir coşkuyla patlarlar. Marinetti'nin okuduğu bu eser için yazılmış metin, sayfada uçuşan farklı büyüklüklerdeki harfler ile çok etkileyici bir grafik eser görünümü kazanmıştır (http://archive.is/MDSQ). 1909'da Paris’te Le Figaro gazetesinde yayımladığı bildiride: 'Bizler müzeleri, kütüphaneleri yerle bir edip ahlakçılık, feminizm ve bütün yararcı korkaklıklarla savaşacağız' derken, aslında geçmişin bütünüyle reddini savunmuştur. $\mathrm{Bu}$ felsefeden yola çıkan Fütürist hareketin katılımcıları çok sayıda manifesto ve devrimci broşürlerle, bilim ve teknoloji çağındaki yeni insan ve yeni sanat projelerini gündeme getirmişlerdir. Bu manifestoların rehberliğinde bir grup İtalyan besteci, 1910 gibi erken bir dönemde, geleneksel müziği reddini savunmuş, makinelerden esinlenerek deneysel sesler üretme amacı gütmüşlerdir. Makineli silahlar, buharlı düdük, sirenler ve farklı gürültü yapıcılar için müzikler yazmışlardır. Fütürist besteciler, geçmişin reddini ve agresif bir şekilde çağdaşlaşma düşüncelerini, gelecekçiliğin bütün zahmetlerine rağmen hayata geçirmeye çalışmışlardır. Buna gürültü makinelerinin yapımı da dahildir (Watkins, 1988 : 310).

Fütürist müzisyenlerin manifestosunu, bu harekete 1910 yılında katılan İtalyan besteci Francesco Balilla Pratella yazmıştır. Pratella, İtalyan müziğinin diğer ülkelerin müziklerine göre daha aşağı bir seviyede ve İtalyan senfonilerin, absürt ve anti müzikal olan operaların etkisinde kalarak olumsuz yönde etkilediğini dile getirerek, o dönemin önemli bestecilerinden biri olan Richard Wagner'i övgüyle anmış ve onun yüce bir dahi olduğunu dile getirmiştir. Besteci 1911'de 'Fütürist Müziğin Teknik Manifestosu'nu, 1912'de de 'Karesel Y1kım' adlı manifestoları kaleme almıştır. O, 'Fütürizmin Kırmızı Bayrağı’ adlı çağırısında; sıradanlık ve tutuculuklara karşın, içleri sevgi ve mücadele ile dolu olan genç bestecileri, gelecekçiliğin ışığına çağırmış, eskiyi tam anlamıyla reddetmeye ve yeni eserler üretmeye davet etmiştir. 
Fütürist akımın müzikteki temsilcilerine Bruitist'ler (gürültü yapıcılar) denir. Bruitist'ler, sadece gürültüyle değil, aynı zamanda mekanik ve elektronikle harekete geçirilebilen ses üreteçleriyle de ilgilenmişlerdir. Bağımsız tarzda yine Rus Fizikçi Franco, Leon Theremin ve Fransız Maurice Martenot 1920'lerde elektronik müziğin öncüleri sayılabilecek, elektronik olarak kontrol edilebilen melodi çalgılarını geliştirmişlerdir. $\mathrm{Bu}$ gelişmeler; Henry Cowell, Edgar Varese, Pierre Schaeffer ve diğer birçok besteci üzerinde derin etkiler bırakmıştır.

Diğer önemli bir Fütürist ise; gürültünün müziğe eklemlenmesinin yollarını açan, 1913 yılında 'Gürültü'nün Sanatı' isimli manifestoyu yazan, ressam ve besteci, Luigi Russolo'dur (Chilvers ve Glaves-Smith, 2009 : 66). Besteci manifestosunda: 'Metal dükkan malzemelerinin çarpışmasının, çarpan kapıların, kalabalıklarının sürtüşmesi ve curcunasının, istasyonlardan, tren raylarından, demir tezgahlarından, dönen millerden, baskı işlerinden, elektrik güç istasyonlarından ve metrolardan gelen çeşitli çınlamaların, zihinsel orkestrasyonunu yaratmaktan keyif alıyoruz' diyerek çağdaşlarına ilham kaynağı olmuş, ilerici düşünceleriyle bu döneme damgasını vurmuştur. Müziğin genel anlamıyla uyumlu seslerden oluşan bir bütün olmadığı fikri ve bu yeni fikirlerin 1şığında gürültünün ve makinelerden çıkan seslerin de müziğin birer parçası olduğu düşüncesi müzisyenleri ve o dönem içerisinde yaşayan bilim adamlarını farklı ses üreteçleri arayışlarına itmiştir. Bu arayışlar aslında sadece 20. yüzyılın başlarında değil ondan önceki süreçte de gündemini korumuş olmasına karşın, Fütürist akımın ortaya çıkmasıyla somut bir hale bürünmüş ve bu dönem içerisinde, teknolojik gereçler kullanılarak yeni çalgıların icat edilmesine vesile olmuştur. 20. yüzyıl bestecilerini derinden etkileyen bu düşünceleri benimseyen Fütürist besteciler, bir anlamda II. Dünya Savaş’ından sonra ortaya çıkacak olan Elektronik Müzik ve Musique Concrete'in de temellerini atmışlardır (Watkins, 1988 : 311).

\section{YENİ ÇALGILAR}

2.1. Theremin: 1920 yılında yakınlık sensörleriyle ilgili Rus devleti tarafindan desteklenen bir araştırma neticesinde Rus Fizikçi Leon Theremin tarafından icat edilmiş ve 1928 yılında patenti alınmış, ilk elektronik ve çalarken temas gerekmeyen, kontrolü iki metal anten arasından sağlanan bir müzik aletidir (Glinsky, 2000 : 26). Orijinal adı Termenvox ve Aetherphone'dur. Daha sonra ismini mucidi olan Leon Theremin'den almıştır. Theremin'deki ses üretimi, resim 1'de görüldüğü üzere; bir el ile titreşim dalgaları gönderilirken diğer el ile sesin şiddeti ayarlanır. İnsan sesine yakın sesler üretilebildiği gibi birçok çalgı efektide yaratılabilir. Beş oktav içerisinde bir nota çalınır ve ses, hoparlörlerle artırılır. Rus besteci 
Dimitri Shostakovich Odna adlı 1931 yapımı filmin müziklerinde ilk olarak orkestra içerisinde bu çalgıyı kullanmıştır. Bu çalgı; Yaylı Dördül, Obua, Piyano ve Theremin için yazılan 'Fantasia for Theremin' isimli eserin bestecisi Bohuslav Martinu gibi bazı bestecilere rağmen, geçici bir zaman dilimi içerisinde işlevsel olmuştur. Leon Theremin ile işbirliği içerisinde olan Amerikalı besteci Henry Cowell, Rhytmican olarak adlandırılan, karmaşık ritmik yapıları çalabilen bir çalgı geliştirmiş, ancak bu çalgı fazla etkili olmamıştır. Theremin, ikinci dünya savaşı ve sonrasındaki dönemde çok ilgi gören bir çalgı olmamıştır.

Theremin: An Electronic Odysse in 1994 adlı filmin yayınlanmasından sonraki süreçte bu çalgı çağdaş besteciler tarafından yoğun bir şekilde ilgi görmeye başlamıştır. Bu besteciler arasında: Percy Grainger, Christian Wolff, Jhoseph Schillinger, Moritz Eggert, Iraida Yusupova, Jorge Antunes, Vladimir Komarov, Anis Fuleihan ve Fazıl Say sayılabilir. Bu çalgı için yazılmış en büyük konçerto; Carolina Eyck için Kalevi Aho tarafından yazılmış: Theremin ve Oda Orkestrası için Sekiz Mevsim adlı eserdir. Yaşayan en önemli Thereminist olan Eyck aynı zamanda Say'ın Mezopotamya adlı 2. senfonisinde de yorumculuğuyla yer edinmiştir. Bu eserde Theremin çalgısı 'meleği' temsil eder. Say: Melek Mezopotamya'yı korusun der (www.sanat.milliyet.com.tr).

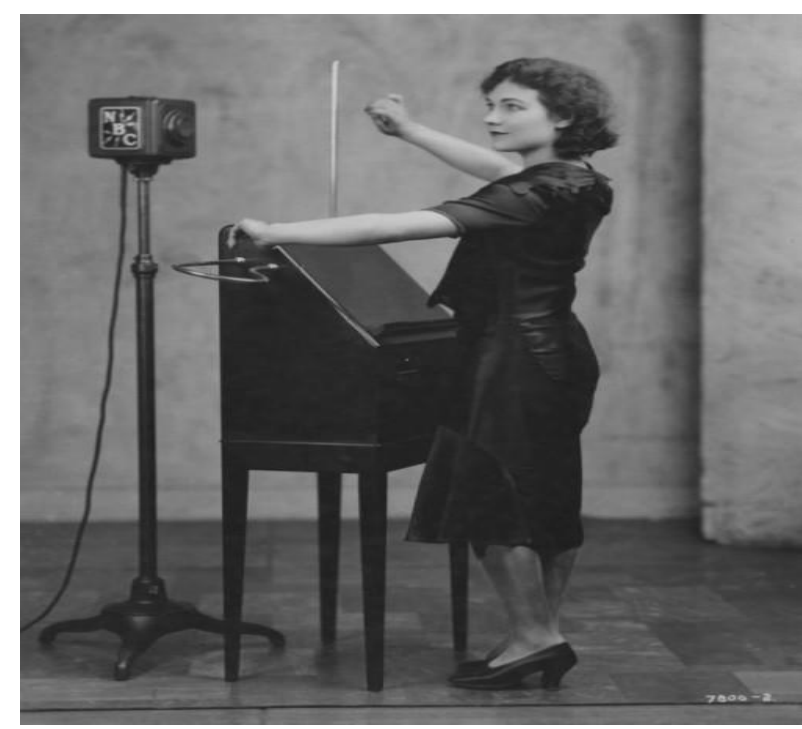

Resim 1

2.2. Martenot'un icadı, Ondes Martenot (martenot dalgaları) ya da Ondes Musicales (müzikal dalgalar): 1928 yılında Maurice Martenot tarafindan icat edilmiştir. Theremin'deki gibi sabit ve değişken dalgalanma ve aynı zamanda icracının elinin hareketleriyle olan uyumu prensibine dayanarak çalışır (Kenet vd. 1998 : 947). Ancak bu, 
Theremin'de daha ilkel bir yapıdayken resim 2'de görüldüğü gibi Ondes Martenot'da ses sınırı altı oktava çıkartılmıştır. Aynı zamanda tek nota çalınabilir, titreşim ve ses yüksekliği kontrol edilebilir ve de glissando etkisi yapabilir hale getirilmiştir. Martenot çok yönlülüğü nedeniyle özellikle Fransız besteciler arasında oldukça popüler olmuştur. 1988 yılında çalgının üretimi durdurulmasına karşın Fransa'daki çeşitli konservatuvarlarda hala bu çalgının eğitimi verilmektedir (Bloch, 2004, s:9). Messiaen ilk olarak 1937 y1lında Uluslararası Dünya Fuarı için yazdığı Fete des Belles Eaux adlı eserinde (Hill ve Simeone, 2005 : 74-75), daha sonra yazdı̆̆ı Saint-François d'Assise adlı operasında, Turangalila-Symphonie'sinde, Honegger'in Jeanne d'Arc au Bücher adlı orotoryosunda, Brian Easdale'ın The Red Shoes adlı bale eserinde, Cemal Reşit Rey’in Ondes Martenot ve Yaylı Çalgılar İçin Poem adlı oda müziği eserinde, Varese'in Ecuatorial, Milhaud'nun Suit for Ondes Martenot and Piano adlı eserleri başta olmak üzere, Maurice Jarre, Sylvano Bussotti, Giacinto Scelsi, Marcel Landowski, Karel Goeyvaerts, Pierre Boulez, Tristan Murail, Miklos Rózsa, Henri Tomasi ve Frank Zappa dahil bir çok besteci eserlerinde bu çalgıyı kullanmışlardır. Andre Jolivet bu çalgı için 1947 yılında önemli bir konçerto yazmıştır (Hilda, 1978 : 188-190). Martenot, film müziğinde de kullanılmış bir çalgıdır. Honegger, Berthold Bartosch'un 1930 yılında çektiği The Idea adlı filmin müziklerinde bu çalgıyı kullanmıştır. 1950'li yıllarda ise ses tınısından kaynaklı olarak, korku ve bilim kurgu filmlerinde bu çalgı sıklıkla kullanılmıştır.

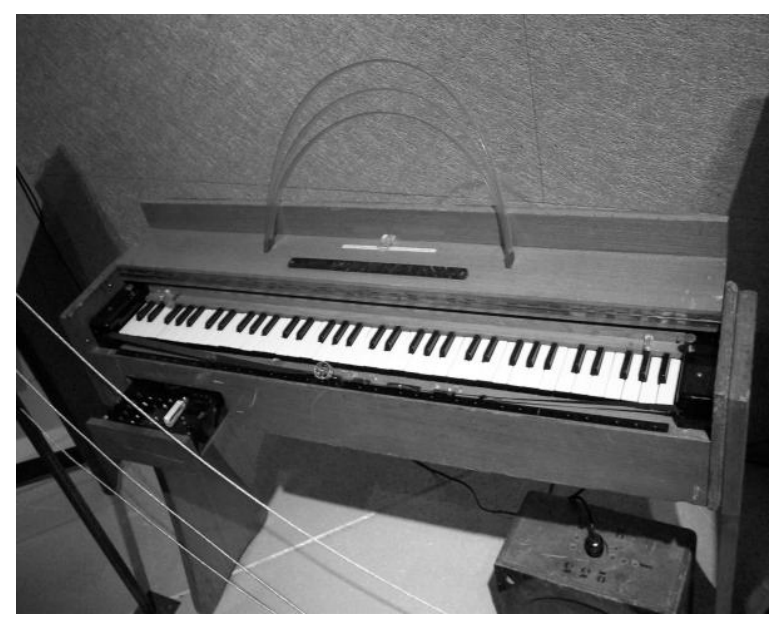

Resim 2

2.3. Intonarumori: İtalyan gürültü makinesi de denen, Luigi Russolo'nun kendisi tarafından, endüstriyel sesleri taklit etmek için tasarladığı çalgı grubuna verilen addır. Besteci tarafından icat edilen ve kullanılan bu çalgı grubu, mekanik sesler ve ritmik motiflerin kolayca üretilmesini mümkün kılar. Bunlar genellikle mekanik olarak harekete geçirilebilir ya da elektrik ile çalışırlar. Russolo bu makinelere birçok fiyakalı isim verir. Örneğin: 
Scoppiatone (patlama makinası), Ululatore (çığlık makinesi) gibi (Kodalyi, 1995 : 210). Russolo, 1913 yılında yazdığı manifesto 'L'Arte dei Rumori'de (Gürültü Sanatı) sanayi devriminin çağdaş insanlara daha karmaşık sesler üretmek için büyük bir imkan sağladığını ve gelecekte, geleneksel melodik müziğin yerini gürültü müziğinin alacağını söylüyordu (ses sanatına kısa bir inceleme). Bir Şehrin Uyanışı (Risveglio di una citta, 1914) adlı eserinde her biri farklı gürültüler üreten 27 değişik tipteki çalgıyı kullanmıştır. Birçoğu II. Dünya Savaşı sırasında zarar görmüş olan bu çalgıların nasıl kullanıldığı hakkında çok fazla bilgi yoktur. Nasıl kullanıldıkları ile ilgili bilgiyi ancak fotoğraflarına bakarak anlayabiliyoruz. Resim 3'teki fotoğraftan görsel hoparlörlerle gürültü makinelerinin kullanıldığı anlaşılmaktadır. Russolo ve asistanının, her biri kocaman, konik birer hoparlör tarafindan sabitlenmiş farklı büyüklükteki kutulardan oluşan Intonorumori'nin kenarlarında durdukları bu fotoğraf, çalgıların görüntülerini yansıtmaktadır. Resimden anlaşıldığı kadarıyla ses üretebilmek için kolları ittirmek gerekmektedir.

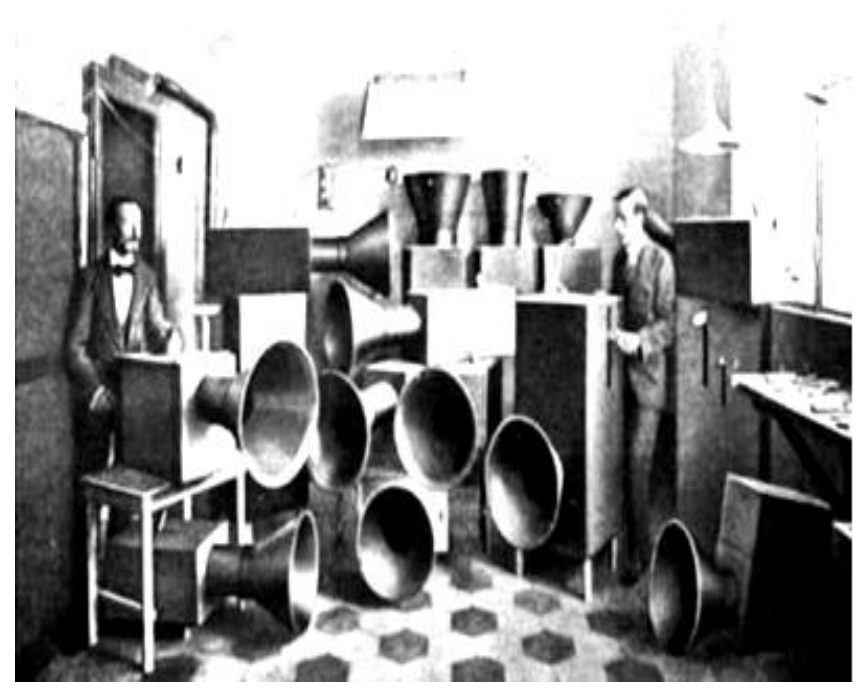

Resim 3

2.4. Vibrafon: 1910 yılının sonlarına doğru Amerika'da icat edilmiş, 1921 yılında Leedy Üretim Şirketi tarafından üretimi yapılıp pazarlanmış bir çalgıdır. Bu yeni çalgı Marimba'nın kullanım prensibine dayanır. Resim 4'te görüldüğü üzere, Vibrafon'un ham maddesi metaldir. Sesi titreştiren her metalin altında elektrikle üretilen pervaneler vardır. Ses sınırı, küçük oktavın fa sesinden üçüncü oktavın fa sesine kadar üç oktavdır. Fakat birinci oktavdaki do sesinden üçüncü oktavdaki fa sesine kadar olan daha küçük boyutlu Vibrafon'lar da vardır. Çalgı bagetlerin metal zemine vurma prensibine dayanır. Bu bagetlerin farklılıkları ses tınısının değişimine sebep olur. Bazı durumlarda dar biçimli farklı akorları çalabilmek için üçüncü hatta dördüncü bagetleri de kullanabilmektedir. Ancak eser yazılırken bu akorların 
çalınabilmesi için mantıksal bir yol izlenmelidir. Sesin gürlüğü titreşim mekanizması eklenerek artırılabilinir. Bu şekilde Kilise orgu tınısı çağrıştırılır. Çalgı, 1924 yılında Edison Kayıt Stüdyo'sunda Signor Frisco lakaplı, Louis Frank Chiha tarafindan "Aloha 'Oe" ve "Çingene Aşk Şarkısı" adlı kayıtlarında kullanıldıktan sonra popüler bir derece elde etmiş ve müzik çevrelerinde daha sık kullanılmaya başlanmıştır (Howland, 1977 : 2). Bu çalgının en önemli ilk icracısı, bir caz virtüözü olan Lionel Hampton'dur. Vibrafon, genellikle dans gruplarında kullanılmış ancak hızlı bir şekilde çağdaş müzik repertuvarında da yerini almıştır. Çalgıyı klasik batı müziğinde ilk kez 1937 yılında Alban Berg Lulu Operasında kullanmış ve bu çalgının aracılığıyla eserin ana kahramanının duygusal portresini ifade etmeye çalışmıştır. Messiaen'in Turangalila-Symphonie ve Trois Petites Liturgies, Milhaud'nun Concerto for Marimba, Vibraphone and Orchestra, Piere Bulez'in Le Marteau Sans Maitre, Benjamin Britten'in Bahar Senfonisi, Igor Stravinskinin Requem Kanticles, Sostakoviçin 14. ve 15. Senfonilerinde ve Stockhausen'in Refrain, Strahlen ve Vibra-Elufa adlı eserlerinde olmak üzere, Marc Bleuse, Jean Barraque, Alan Chan, Chridtopher Deane, Morton Feldman, Lior Navok, Andersen Viana ve Vaughan Williams dahil birçok besteci bu çalgıyı eserlerinde kullanmıştır.

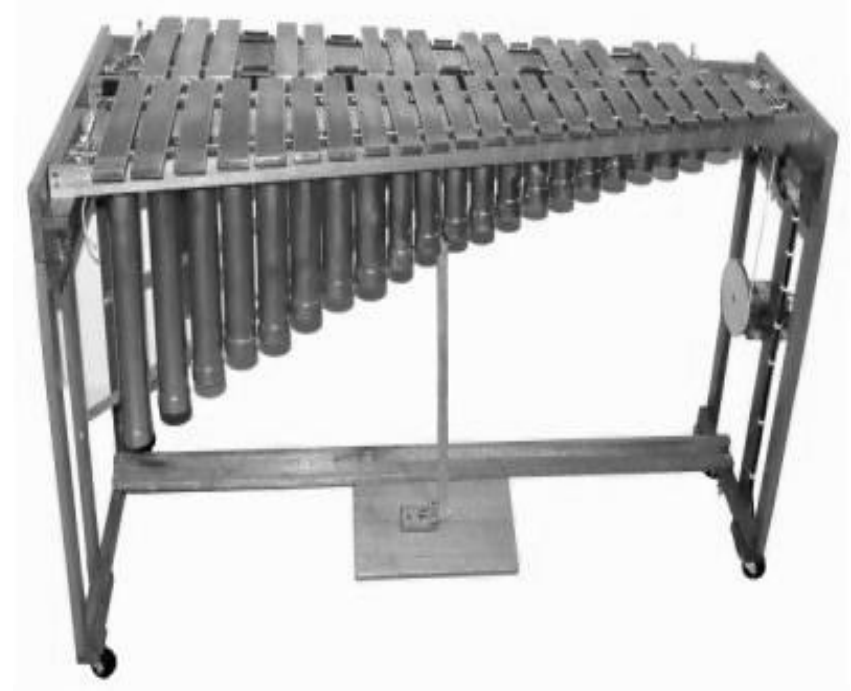

\section{Resim 4}

2.5. Hazırlanmış Piyano: İlkel biçimi ile 1711 yılında İtalya'nın Floransa kentinde, Bartolomeo Cristofori tarafindan keşfedilen Piyano, o tarihten bu yana çalma teknikleri açısından sistematik bir gelişme göstermiştir. Piyano, müzik literatürünün en önemli eserlerinin yazıldığ olmuştur. Hazırlanmış piyano ise edebiyatçı ve Amerika'nın en önde gelen bestecilerinden 
Kalifornia doğumlu Henry Cowell tarafından keşfedilmiştir. Besteciden önceki dönemlerde Avrupa'ya sadece eğitim almak ve kendilerini geliştirmek için giden Amerikalı müzisyenlere karşın, besteci I. Dünya savaşı sonrası Avrupa'da yeni ve deneysel müzik arayışı gündemdeyken, 1923 yılında bu coğrafyaya Amerikan modern müziğini tanıtmak için bir turne düzenlemiş, bu turne için 'Piece for Strings' adlı eserini yazmıştır. Diğer piyano eserlerinden farklı olarak bu eserde, piyanonun tellerine el ile müdahale edilerek farklı tınılar elde edilmesi sağlanıyordu. Cowell o güne kadar hiçbir yerde sözünü etmediği bu yeni müzikal kaynak için 'string piyano' adını uygun gördü (Hicks, 2002 : 110). Bu turneden döndükten sonra New York'ta bazı piyanistler, piyanonun telleri üzerinde çalmayı müzikal ahlaksızlık olarak değerlendirmişlerdir (Pelham, 1924 : 34). Çek piyanist Ludvik Kundera gibi birçok müzisyen de Cowell'in alışılmışın dışındaki tekniklerini, kompozisyon tekniğindeki yetersizliklerini örtmek için kullandığını iddia etmişlerdir (Drlikova, 1988 : 5859). Piyano tellerinin tınısı bestecinin keşfinden önceki süreçte de araştırılmaya başlanmıştır.

Piyano yapımcıları 19. yüzyılın başlarında, Türk müziğindeki Simbal (zil) efektini üretebilmek için pirinçten yapılmış çubuklarla piyanonun kalın sesler çıkaran tellerine, davul efekti için çalgının arkasındaki ses tahtasına vurarak, fagot çalgısının ses tınısını üretebilmek için ise tellerin üstüne parşomen kaplı bir tahta dayama ve daha birçok yolu deneme sureti ile farklı ses renkleri üretme yoluna gitmişlerdir. Ancak bu gibi tını üretme yöntemlerini geliştirmek ve bu tekniğin isim babası olmak Cowell'a nasip olmuştur. Hazırlanmış Piyano, çalgının içindeki tellerin doğrudan el ile çalınması, titreşen tellerin el ile susturulması, parmak etleri ya da parmak uçları ile tellerde glisando yapmak, avuç içi ile tellere yavaşça vurmak, telleri parmaklarla çekerek çalmak gibi fiziksel hareketlere imkan sağlar. Bunların yanında, çalgının içine değişik metal ve tahta objeler, demir para, vida, iğne ve bu gibi materyalleri tellere sürterek tını elde etme yoluyla yapılır.

Cowell'ın öğrencisi olan John Cage hocasından oldukça etkilenmiş ve onun izinden giderek 'Hazırlanmış Piyano' fikrini daha da geliştirmiş, hatta bu çalgı için bestelenen eserlerin en yaratıcı olanlarını yazmıştır. Cage 1940 yılında, Amerika'lı dansçı Syvilla Fort'un bir dans gösterisi için yazdığı Bacchanale adlı eserinde ilk kez hazırlanmış piyanoyu kullanmıştır (Margo, 2004). Besteci aslında vurmalı sazlar için yazmayı düşündüğü bu eserini, dans gösterisinin geniş bir salonda yapılamamasından kaynaklı olarak sadece piyano için yazmıştır. Çalgının tellerini birbirlerine bağlayıp, aralarına lastik, tokmak, tahta gibi değişik cisimler yerleştiren besteci piyanonun geleneksel tınısını vurmalı sazlar grubunu andıran sessel bir yapıya büründürmüştür. Resim beşte görüldüğü gibi besteci piyanonun 
tellerine gerekli düzenlemeleri yaparak eserin çalınmasına uyumlu hale getiriyor. Hazırlanmış Piyano için, John Brennan Kurt, Roberto Carnevale, Philip Corner, Stephen Scott, Richard D. James, Jason Moran, Erdem Helvacioğlu, Marina Leonardi, Hiromi Uehara ve Volker Bertelmann adlı besteciler eserler yazmışlardır.

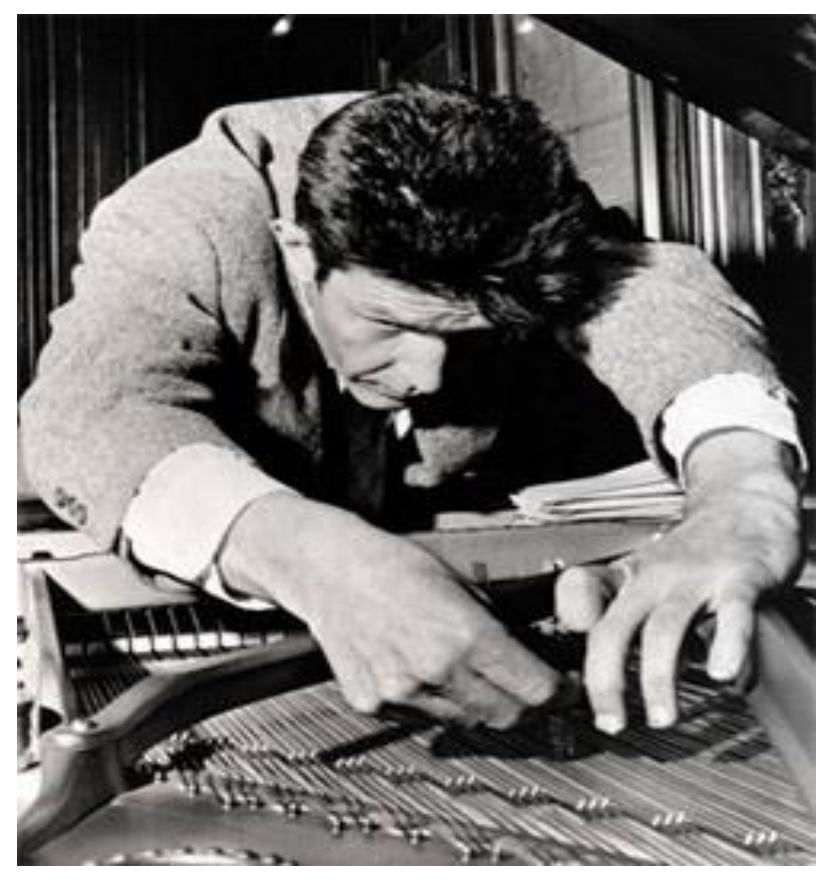

\section{Resim 5}

2.6. Partch'ın Çalgıları: Cowell gibi öncü bestecilerden biri olan Partch, katı batı sistemini reddetmiş (Yang, 2008 : 53), oryantal ve pratik teorileri takip ederek, bir oktav içerisindeki on iki yarım ses yerine, kırk üç yarım sesin kullanıldığg mikrotonal sistemi benimsemiştir. Besteci kendisi için mobilyaların baştan çıkardığı felsefik bir müzik adamı yakıştırmasında bulunmuştur (Harrison, 2000 : 135). Besteci 1930 yılında ilk özel çalğısı olan, uyarlanmış viyolayı tasarlamıştır. Müziği, fiziksel ve tiyatro kökenli olup daha çok oyunculuk, dans, şarkı söyleme, çalgısal müziğin yarı ayinsel tecrübe için harmanlandığı klasik Yunan Draması, Japon Noh ve Kabuki adı verilen dans tiyatrolarındaki oyun formundadır. Besteciye göre insan bedeninin tümü sanata dahil edilmelidir. Bestecinin 1947 yılında yayınladığı Genesis of a Music kitabında kendi teorilerini anlatııştır. Buna rağmen Partch kendi çağdaşlarıyla aynı fikirde olup, geleneksel çalgıların kısıtlayıcı etkilerinden dolayı kendi mikrotonal fikirlerinin ve tasarladığı çalgıların müzik sanatı içerisinde kolayca icra edilemeyeceğini kabul etmiştir. Bu memnuniyetsizliği, besteciyi büyük ölçüde Polynesian (orta ve güney Pasifik Okyanusu üzerine dağılmış 1000'den fazla adadan oluşan bölgeye ve bölge müziğine verilen isim) örneklere dayanan, yeni vurmalı çalgıların yapımına zorlamıştır. $\mathrm{Bu}$ yeni çalgılar, görsel olarak oldukça dekoratiftir. Örneğin: gourd tree 
(balkabağı ağacı) ve cone gong'ları oryantal vurmalı çalgılara benzer. Partch, aynı zamanda Marimba ailesini de kendi icatlarıyla geliştirmiş, Bas Marimba ve Marimba Eroika'yı da tasarlamıştır. Chromelodeon diye adlandırılan, oktav başına kırküç mikroton çalabilen org da bestecinin icatları arasındadır. Besteci bu çalgıyı 1951 yılında yazdığı 1952-1954 ve 1967 yıllarında tekrar yapılandırdığı Oedipus adlı operasında, 1960 yılında yazdığı Revelation in Courthouse Park ve 1965 yılında başlayıp 1966 yılında tamamladığı Delusion of the Fury adlı eserlerinde kullanmıştır. Bestecinin 1976'daki ölümüyle birlikte hem müziği hem de icat ettiği çalgılar unutulmuştur. Resim altıda bestecinin kendi yapmış olduğu bir kısım çalgıyla fotoğrafını görmekteyiz.

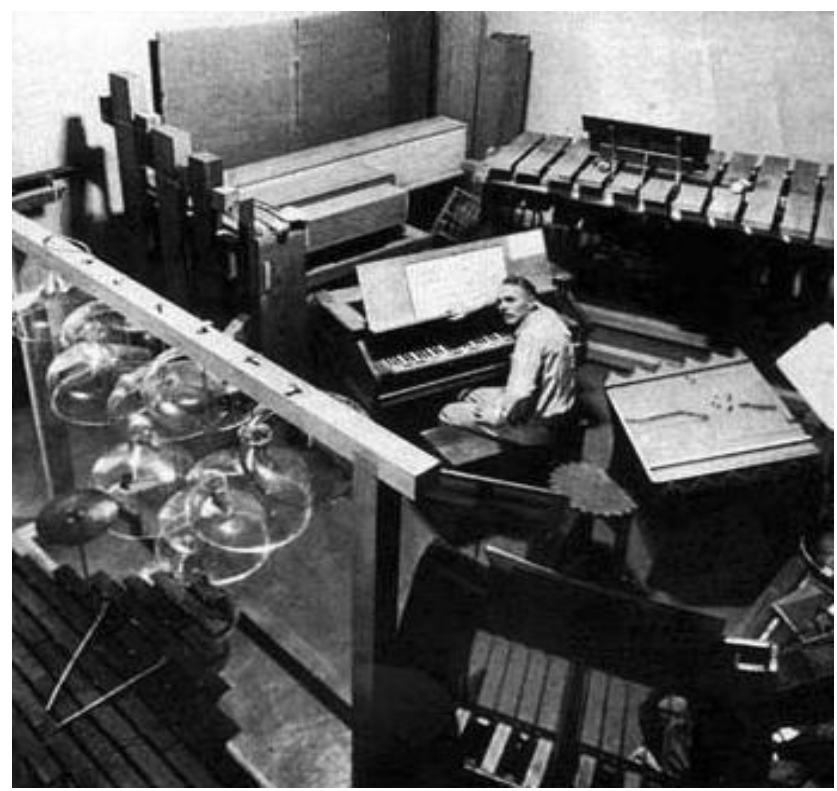

\section{Resim 6}

\section{Sonuç}

Görülüyor ki 20. yüzyılın başlarında, Fütürizm akımının yoğun etkileri çerçevesinde ortaya çıkan yeni çalgılar ve bu çalgıların yeni tınıları, birçok besteci için merak uyandırmış ve yaratıcı eserlerinde yer edinmiştir. Ancak bu çalgılardan sadece bir kısmı belirli bir zaman dilimi içerisinde işlevselliğini korurken bir kısmı da unutulmuştur. Son dönemde ise özellikle Theremin çalgısının kullanımını günümüz bestecileri tarafından sıklıkla tercih edilmektedir. Bunun yanında Vibrafon'da orkestra eserleri içerisinde yerini almaktadır. Aslında Fütürist akımın etkisiyle ortaya çıkan bu yeni tını arama isteği, 20.yüzyılın başlarından itibaren yazılan birçok yenilikçi eserle birlikte, var olan çalgıların ses sınırlarını ve tekniksel özelliklerini geliştirme yönüne kaymıştır. Bu gelişimle beraber klasik çalgılardaki yeni tını arayışları yine 1900'lü yılların başlarında önemli boyutlara ulaşmış, bu tını arayışları yeni 
notalama biçimlerini de beraberinde getirmiştir. Fütürizm akımı, II. Dünya Savaş'ından sonra ortaya çıkacak olan Elektronik Müzik ve Musique Concrete'in temellerinin atılmasına zemin hazırlamıştır (Watkins, $1988: 311$ ).

\section{Kaynaklar}

BLOCH, Thomas (2004). Music for ondes Martenot, Naxos Records CD 8.555779 albüm notlarından,

CHILVERS, Ian. GLAVES-SMITH, John (2009). A Dictionary of Modern and Contemporary Art. Oxford University Press, İngiltere.

DRLIKOVA, Eva (1988). Henry Cowell, Leos Janacek and Who Were the Others?, Sonneck Society Bulletin. XV/2,

GLINSKY, Albert (2000). Theremin: Ether Music and Espionage. University of Illinois Press, A.B.D.

MARGO,Jefferson. $\quad$ http://www.nytimes.com/2004/11/06/arts/design/06jeff.html?_r=0 Renewing Their Vision by Mining Ancient Worlds. The New York Times gazetesi 06.11.2004, Erişim tarihi: 18.12.2013.

HARRISON, Lou (2000). Harry Partch: An Anthology of Critical Perspectives. Psychology Press, A.B.D.

HOWLAND, Harold (1977). The Vibraphone: A Summary of Historical Observations with a Catalog of Selected Solo and Small-Ensemble Literature; say1 13, no. 2, A.B.D.

HICKS, Michael (1991). The Imprisonment of Henry Cowell, Journal of the American Musicological Society. XLIV/1, A.B.D.

HICKS, Michael (2002). Henry Cowell, Bokemian. Chicago: University of Illinois Press, A.B.D.

HILDA, Jolivet (1978). Avec André Jolivet, Flammarion, Fransa.

HILL, Peter, SIMEONE, Nigel (2005). Messiaen. Yale University Press, A.B.D.

KENNET D., Skeldon. LINDSAY M., Reid, VIVIENE, McInally. BRENDAN, Dougan. CRAIG, Fulton (1998). Physics of the Theremin, American Journal of Physics, 66, 11:945-55, A.B.D.

KODALYI, Otto (1995). Introducing Modern Music, Published by Penguin Group, New York, A.B.D.

MCGEAR, Thomas (1992). Bitter Music: Collected Journals, Essays, Introductions, and Librettos. University of Illinois Press, A.B.D.

PELHAM, Adrian (1924). Music/Stravinsky and Cowell Break the Ice of Tradition, Theatre Magazine,

WATKINS, Glenn (1988). Soundings, Schirmer Books, New York, A.B.D.

YANG, Mina (2008). Harry Partch, the Hobo Orientalist. University of Illinois Press, A.B.D. 
http://sanat.milliyet.com.tr/fazil-say-dan-bir-dunya-

promiyeri/muzik/haberdetay/20.06.2012/1556262/default.htm, Fazıl Say'dan Bir Dünya Prömiyeri, Yayınlanma tarihi: 20.06.2012, Erişim tarihi: 12.12.2013

http://archive.is/MDSQ, A Brief Survey of Sound Art, Erişim Tarihi: 11.12.2013

Resim 1: http://viola.bz/theremin-and-theremists/ Erişim tarihi: 10.12.2013

Resim 2: http://commons.wikimedia.org/wiki/File:Ondes_Martenot_(1960).jpg, Erişim tarihi: 10.12.2013

Resim 3: http://www.musicofsound.co.nz/blog/intonarumori, Erişim tarihi: 10.12.2013

Resim 4: http://www.buildavibraphone.com/get_vibraphone_plans.html, Erişim tarihi: 10.12.2013

Resim 5: http://digitalpug.wordpress.com/2013/11/24/john-cage-silence-vs-noise/, Erişim tarihi: 10.12 .2013

Resim 6: http://www.sonoloco.com/rev/innova/401-405-406/partch.html, Erişim tarihi: 10.12 .2013 